\title{
Studies on the Human Resource Management of X Company in Tai'an City, Shandong Province
}

\author{
Xiujuan Wang ${ }^{1,2}$, Jilian $\mathrm{Hu}^{{ }^{*}}$ \\ ${ }^{1}$ School of Economics and Management, Shandong Agricultural University, Tai'an, China \\ ${ }^{2}$ College of Foreign Languages, Shandong Agricultural University, Tai'an, China \\ Email: xjw9007@126.com, “ilhu@sdau.edu.cn
}

Received 8 September 2015; accepted 9 October 2015; published 12 October 2015

Copyright (C) 2015 by authors and Scientific Research Publishing Inc.

This work is licensed under the Creative Commons Attribution International License (CC BY). http://creativecommons.org/licenses/by/4.0/

(c) ()

\begin{abstract}
With the development of China's market economy, variety of enterprises have made considerable development. And they made great contributions on strengthening the comprehensive development for China. The problems existed in human resources management has restricted the further development of the enterprise. By doing comprehensive research on the present situation of human resource management of an enterprise in Tai'an city, we try to analyze the specific problems existed in human resource management and to put forward a series of solutions.
\end{abstract}

Keywords

X Company, Human Resource Management, Family-Owned Company

\section{Introduction}

Human resource management includes activities that are conducting job analysis, planning personnel needs, recruiting right people for the job, orienting and training, managing wages and salaries, providing benefits and incentives, evaluating performance, resolving disputes, and communicating with all employees at all levels [1]. Examples of core qualities of HRM are extensive knowledge of the industry, leadership, and effective negotiation skills. Different from traditional human management, modern HRM regards staff as a valuable resource, more dynamic and inclined to strategic height [2].

Human resource management started late in China. The theory of human resource management wasn't introduced to our country by multinational companies until the late of 1970s [3]. From the view of time, the human

${ }^{*}$ Corresponding author.

How to cite this paper: Wang, X.J. and Hu, J.L. (2015) Studies on the Human Resource Management of X Company in Tai'an City, Shandong Province. Open Journal of Business and Management, 3, 380-388.

http://dx.doi.org/10.4236/ojbm.2015.34037 
resource management in China is far behind the western developed countries. After the reform and opening up, especially after China's accession to the WTO, market competition is more and more intense. With foreign companies flooding in, old human management already cannot be adapted to the development of economy [4]. Companies are in the continuous reform of the traditional human management so as our national system. The system of human resource management is gradually formed, which represents the specific characteristics of China.

Although many aspects of human resource management are formulated in laws, there are a lot of enterprises which are still in the stage of traditional human management. With the development of market economy, enterprises in our country, especially private enterprises, have obtained rapid development [5]. They have made great contributions to the development of Chinese economy and the improvement of people's living standard. But with the process of economic globalization and China's accession to the WTO, unperfected human resource management has been a major problem which is restricting the development of itself [6]. GE's chairman and CEO Jack Welch spent more than $50 \%$ of his working time on human management. He considers his greatest achievement in training and taking care of the talents. So, what about the status of human resource management in our country? What kind of problems do we have? Those are the issues we try to solve.

\section{Analysis of X Company}

\subsection{Macro Analysis}

\subsubsection{Company Profile}

Tai'an is a middle city in Shandong province and X Company is a branch of Shanghai X Company. Shanghai X Company was founded in 2006. Tai'an X Company was built in 2009. Today, X Company has five 24-hours branch in Shanghai and Tai'an [7]. It is one of the most famous leisure clubs with the characteristic of Korea. With Korean fire bath as its main feature, X Company provide customers with thoughtful one-stop service, including spa bath, fitness center, massage and hairdressing, AV board, coffee canteen, children's playground, outdoor swimming pool and so on [8]. The style of its decoration, the service provided by multi-functional leisure system and the perfection experience through physical and mental pleasure make many customers to linger.

\subsubsection{Political Factors}

Tai'an X Company belongs to resident service industry. Law of the PRC on Public Security Administration was carried out in 2006. It is published to maintain social order, safeguard public security and protect the legit rights and interests of citizens, legal persons and other organizations. What is more, it makes clear rules for organs and police to perform their duties. Started late, there are many drawbacks. It was revised in 2012. Besides the Law of the PRC on Public Security Administration, X Company must respect all aspects of national legal system.

In addition, since China joined the WTO and the influence of the population flow; many companies are run by Koreans. China has become Korea's largest foreign investor. Our government supports foreigners to operate companies in our nation for they can help creating more employment opportunities, promoting economic development and activating the local market.

\subsubsection{Economical Factors}

Our economy has been recovered since the outbreak of the financial crisis in 2008. Macro-economy runs smoothly in 2014. The economic growth keeps in a reasonable range. There are some positive changes and points in economy.

However, there are still some outstanding problems and contradiction in economy, including insufficiency in investment growth, obvious constraint of financing bottleneck and obvious problems in managing companies.

In addition, bath market has been more and more competitive. Customers prefer sauna centers which can provide better services.

\subsubsection{Social and Cultural Factors}

According to 2014 census data, the population of Tai'an is more than 9 million. About $10 \%$ of the population is immigrant population. And, a large part of immigrant population is from Korea. Many Koreans have come to China to build factories since China and South Korea has established diplomatic relations in 1992. What is more, 
Korean company's workers and their children immigrate to China. With their arrival, it not only promotes the development of economy, but also brings the culture of Korea. In recent years, people, especially young men and women, prefer Korean Costume and their makeup. They love not only Korean style, but also their living habits, such as having break at leisure club. As Korean sauna center, its consumer groups are Koreans and Chinese who love Korean style. Here, they can imitate Korean living habits to enjoy leisure entertainment, such as wearing a claw cap which is popular from Korean drama, drinking rice juice and enjoying sauna. However, because of financial crisis, as well as the transformation of industrial structure and the rising of labor capital, many Korean companies withdrew from Tai'an.

With China's strategy of invigorating the country through science, technology and education and the improvement of people's living standards, many students have the opportunity to further their study in Korea. At the same time, they get used to living like Koreans. They will bring Korean living attitude when they return. Many young people are willing to imitate. They have fun in sauna center like Koreans. In addition, to get rid of their pressure, many people are willing to relax their body and mind in sauna center. Enjoying in the sauna center has become an indispensable part of people’s life.

\subsubsection{Technological Factors}

Firstly, for sauna industry, its technology is mainly reflected in facilities and equipment. It is measured whether they can provide customers with more comprehensive services. At the time of its beginning, people used to burn mineral stone and splash water on it to produce steam. Nowadays, we use infrared ray and negative ions to reach the effect of sauna. Sauna is divided into two categories, dry sauna and wet sauna. So, there is different sauna room. Featuring Korean style gives X Company an edge. Its specialty is fire bath room.

Secondly, as high water consumption industry, its technology lies in the water transport and handling system. Since its founding, X Company uses circulating water system in tangquan. Water is changed every day. What is more, they clean pipes regularly in order to maximize the effect of the system.

Thirdly, its technical level reflected in the massage service. X Company's Korean style is also lying in this aspect. They provide Korean massage using drug to stimulate meridian, such as ear candling, kneeling back and beauty project.

\subsection{Present Situation Analysis of HRM}

\subsubsection{Human Resource Planning}

Human resource plans are the important basis for laying down strategic goals. It plays an important role in meeting the company's demand for human resource.

According to the operating factors such as the flow of customers and opening time, X Company needs workers up to $81^{1}$. Operating manager is mainly responsible for in-store affairs. He is also the manager of the department of HR.

Considering factors such as market situation in Tai'an and the status of it, X Company is going to open a store in Taishan district. Therefore, in terms of demand for human resource, the HR department should do a good job in predicting supply and demand for HR. According to the survey, labors that are willing to engage in sauna industry are not enough. As a result, X Company lacks for talents who are experienced and good at management. According to the present situation of local human resource, the manager chooses to transfer employees from Shanghai to Tai'an. As for the need for junior staff, it is mainly satisfied through various recruitment channels from local HR market.

HR plans includes the overall plans and various basic plans. Since the establishment of it, Tai'an X Company imitates Shanghai X Company in laying down HR plans. However, overall plans makes little changes every year so as basic plans. For X Company, these works are mainly finished by the headquarters. Stores do not pay much attention to this part of work.

\subsubsection{Recruiting and Configuration}

Recruiting refers to the process of finding and hiring the best-qualified candidate (from within or outside of an organization) for a job opening, in a timely and cost effective manner.

After determining the vacancy, HR department can timely make recruitment strategy by applying a variety of

\footnotetext{
${ }^{1}$ Data source: all data collected by interview survey among managers and employees working in X Company.
} 
recruitment channels to attract job hunters in advance. Main recruitment channels are Internet recruitment, job fair and advertisement-release. With the rapid development of information technology, the computerization of HR management has become a trend, like online recruitment mode. X Company mainly use Ganji to recruite employees, which can reduce the burden of recruitment. X Company choose North Station as its job fair. The center district of Tai'an is a representative of Tai'an service industry. Therefore, human resource is relatively abundant there. Companies in Taishan district mainly belong to manufacturing. So, most enterprises on North Station belong to it. Candidates who come here prefer to find a job in factory. But new manager who was transferred from Shanghai didn't know it. It caused waste without efficiency.

For job applications, first of all, HR department select the ones which are content with requests. Then, they will be interviewed by telephone to invite them to have an interview in our company. Interview methods are relatively simple, which are mainly the combination of free interview and situational simulation test. Interviews for junior staff are conducted by HR assistant. She will decide whether to employ. Interviews for foreman and above are conducted by manager.

$\mathrm{X}$ Company runs 24 hours a day and all the year round. It is the peak period of employee turnover near the end of the year. What's worse, it is also difficult time for HR department to recruit people. At this time, $\mathrm{X}$ Company mainly adopts the method of internal recruitment. It hopes employees to work overtime. Furthermore, it encourages them to recommend people around them to work in the company. After the Spring Festival, the number of job hunters applying for jobs is enough. So, it is easy for the company to get vacancy filled. As sauna industry, there are peak-season and off-season. When summer comes, low season comes too. At this time, it only needs to maintain normal number of employees. Even if there is a little shortage, it can be satisfied by extending working time on condition that employees agree. And proper pay for overtime is necessary.

According to the survey, appropriate percent of employee turnover is between $10 \%$ and $15 \%$. China's average employee turnover is $15.9 \%$ in 2013. During February to May, X Company's employee turnover is much higher, especially in February and March. The turnover of X Company employee is shown in Figure 1.

\subsubsection{Training and Development}

Training and development refers to the official and ongoing educational activities within an organization designed to enhance the fulfillment and performance of employees. Training and development programs offered by a business might include a variety of educational techniques and programs that can be attended on a compulsory or voluntary basis by staff.

The content of the training includes knowledge, skills and attitude training. As a service industry, X Company's training is mainly aimed at staff on scene. The company pays more attention on skills training and attitude training. However, it ignores knowledge training, which is particularly important for senior managers and other departments. Skills training towards employees on scene focus on training their operation skills and communication skills. They help workers to communicate better with customers, provide satisfied services and set up company's image.

From the view of training form, it includes pre-job training, job training and job-transfer training. Pre-job training is mainly conducted by HR assistant. HR assistant will make it clear to new employees, such as present situation, culture, rules and regulations, work environment, the content of the work and so on. It makes employees to have a thorough knowledge of their work. Operation training is mainly conducted by foreman or supervisor. X Company will train employees irregularly. The content of the training is mainly about cultivating

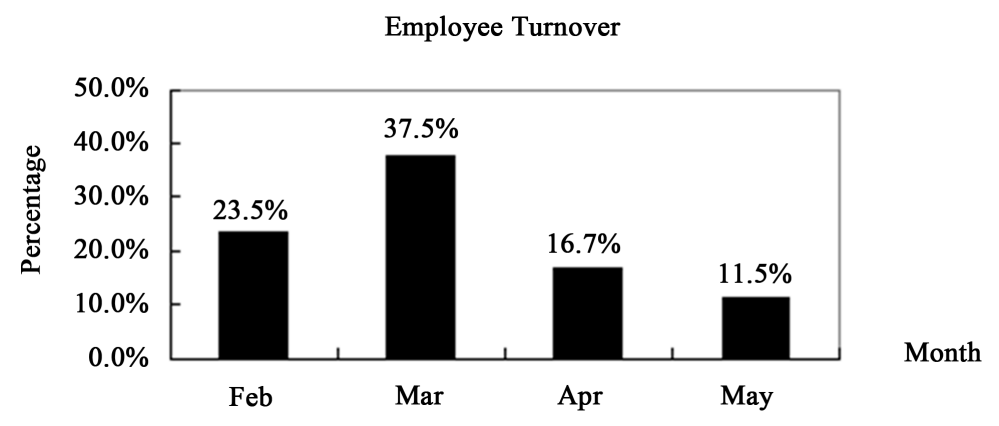

Figure 1. The turnover of X Company employee. 
and training staff operation abilities. It helps to make their work efficient and provide better services for customers. In X Company, job transfer is less. As a result, job-transfer training is mainly conducted by the head of the department. However, training in X Company is mainly short-term training. It performs well in the short term, but is not profound. However, there is no long-term training for employee. In other words, X Company doesn't combine the need of the company's development with employee's career.

$\mathrm{X}$ Company mainly adopt the training method like lecturing, behavior imitation and apprentice training. It is mainly conducted by the manager. He will tell employees about culture, values and other content such as operation instructions. To solve the conflicts with customers, the manager will give employees solutions, and require them to imitate, which can cultivate their abilities to deal with emergency and avoid losses for economy and HR.

\subsubsection{Performance Management}

Performance management refers an assessment of an employee, process, equipment or other factor to gauge progress toward predetermined goals. According to the survey, X Company makes evaluations for foremen, supervisors and managers on their performance. According to the nature of their work, it is carried out mainly to evaluate their ability and attitude towards work. Ability evaluation aims to find out whether they have organization and coordination ability, analysis the judgment ability, leadership ability, guiding ability, executive ability and learning ability, etc. What is more, the assessment of manager's ability is aimed to see if they have the ability of innovation and authorization. While doing attitude evaluation, it is aimed to examine their activity, enthusiasm, sense of responsibility, initiative and collaborative, etc. X Company uses rating scale method to evaluate all aspects of employees. After the evaluation, it is important to reach conclusions, which can be the basis of compensation management. Furthermore, it helps middle managers to improve performance, ability and management level.

Performance evaluation includes monthly evaluation and annual appraisal. But poor management in branch, performance management is less carried out, which makes performance management meaningless. As for performance evaluation on managers, the lack of professional makes it difficult.

In addition, $\mathrm{X}$ Company only makes performance evaluation for the middle managers, not mention the junior and other department staff.

\subsubsection{C \& B Management}

Compensation is one of the most basic means for an organization to motivate its members. Western countries put forward the comprehensive compensation including not only the material income but also spiritual benefits. Compensation management is a process that an enterprise through the services provided by employees determine what total compensation, compensation structure and compensation form they should receive and make a compensation adjustment and control.

X Company’s salary structure includes basic salary, performance pay (only a one-time bonus) and welfare, except incentive pay. Using position compensation system to determine the basic salary, X Company mainly uses position ranking method. According to the relative value of each work in the company, we put them in order and then compare them with the similar enterprises to determine the level of wages. This method is relatively simple. The cost is low. But the lack of quantitative analysis makes evaluation standards vague. Position compensation system is used to determine office, financial room, and business office employees' basic salary.

There were fewer competitors when X Company set up in Tai'an. But now, with competitors growing, X Company is at disadvantage. X Company has changed differential salary strategy to contract salary strategy.

Disappointedly, the legal benefits are not carried out in X Company. In terms of company's welfare, X Company set up overtime fee, free dormitory, free lunch, festival bonus and organized travel welfare, etc.

\subsubsection{Labor Relationship Management}

X Company belongs to private enterprise. There are general problems existing in private enterprises. Labor relations include types of conflict interest, coordinate interest and common interest. In X Company, conflict interest type occurs when employees think their wages unfair. X Company's key positions are taken by the board's relatives and friends, for example position in financial room, warehouse department and purchasing department. At the beginning, family management is of great benefit to the development of the company. But with the change of situation and the growth of the company, disadvantages will be gradually revealed. One of them is the contradiction between family members and non-family members. 
X Company's employees are in a weak position. Senior manager and family members determine the company's rules and regulations. Junior members rarely take part in the operation and management of the company. So, democratic concepts and ideas haven't been well developed. High employee turnover, lack of enthusiasm and low work performance will restrict the development of the company to a great extent.

\section{X Company's Problems Existed in HRM and the Cause Analysis}

\subsection{Problems Existed in Human Resource Plans}

\subsubsection{Overall Plans Are Not Scientific}

Shanghai X Company, founded in 2006, has a considerable market share. Shanghai Free Trade Zone was established in 2013. The change of macro environment can bring influence on the development of X Company. From the view of human resource plans, X Company does not fully analyze the macro environment. In other words, while the external environment is constantly changing, $X$ Company does not make timely adjustment to overall plans in the next period. It causes the overall plans inappropriate and unpractical. In addition, although headquarter is doing this part of the work, it does not execute well in every store. Inadequate guidance, weak supervision and disappointing management make it hard for the branch in Tai'an to carry out overall plans. And the inappropriateness of overall plans will make basic plans absent.

\subsubsection{The Lack of Basic Plans}

Overall plans are not scientific result in the lack of basic plans. Seen from the reality, X Company has done part work of basic plans: specifying the goals and policies of the basic plans, except budget for each plan. Lack of budget will make cost control useless. As a result, it will affect company's profits and its further development.

\subsection{Problems Existed in Recruiting and Configuration}

\subsubsection{Improper Recruitment Channels}

Network is a new channel for recruiting. X Company only chooses Ganji. It is relatively narrow; X Company chooses North Station as its job fair. The center district of Tai'an is a representative of Tai'an service industry. Therefore, human resource is relatively abundant there. Companies in Taishan district mainly belong to manufacturing. So, most enterprises on North Station belong to it. Candidates who come here prefer to find a job in factory. So, it is a mistake to choose North Station. This is not only a waste of recruitment cost, but also little effect; through releasing recruiting advertisements, it can make up for the inadequacy of two channels above. But on the choice of time and place, recruitment was not smooth, for new managers did not understand distribution of labor in Taishan district. It caused the waste of manpower, material and financial resource.

\subsubsection{High Employee Turnover}

High employee turnover has been common shortcoming of the service industry. From Figure 1, employee turnover have been far more than normal in February and March. During the Spring Festival, employees who wish to reunite with family can only choose to leave. Higher employee turnover is not beneficial to the stable development of the company. Furthermore, the loss of experienced staff will cause the loss of human resource.

\subsection{The Problems Existed in the Training and Development}

\subsubsection{No Knowledge Training for Employees}

Knowledge related to work is the primary content of training. According to the survey, employees' educational background is below college level. Low cultural quality needs HR department to carry out knowledge training. Knowledge, in psychology, sociology, culture and ethics, management, organization's development strategy and culture, has great benefits for employees to work better. Moreover, it is appropriate to have different knowledge training for different departments.

\subsubsection{No Long-Term Training for Employees}

Short-term training has stronger pertinence and immediate results. But the effect isn't profound. It is needed to combine the company's development needs with employee's career when long-term training is carried out. The state that the company lacks of talents requests X Company to spend on training willingly. The company should 
select the right long-term training for employees, especially for senior managers, which can promote the company's development in return.

\subsection{The Problems in Performance Management}

\subsubsection{Lack of Working Performance Evaluation}

Working performance evaluation can measure an employee's contribution to the company. It can provide basis for reasonable compensation. X Company did not set up this evaluation. Working performance evaluation has great significance on evaluating high-level managers' work.

\subsubsection{The Lack of Professionals}

To carry out performance evaluation, professionals are needed. X Company lacks of professionals. And its work is assigned to middle managers or someone else appointed by senior managers. As a result, the work of performance evaluation can't run smoothly. The company can't have a comprehensive grasp on employees' actual work condition, which will affect other aspects of HRM work.

\subsection{Problems Existed in C \& B Management}

\subsubsection{Improper Constitution in Technicians' and Help Bath Department's Wages}

For the two departments, their wages consist of commission. Although technicians and help bath department are contracting departments, its earnings take over fifty percent of the company's revenues. So, it is necessary for X Company to standardize the management of the two departments. Except asking them to carry on training, $\mathrm{X}$ Company should standardize their operation process. It is forbidden for them to recommend or provide expensive services which are not approved by customers. But in practice, it happens, which is connected to their improper constitution in wage.

\subsubsection{Do Not Meet National Statutory Welfare Requirements}

The legal benefits are not carried out in X Company. On the one hand, employees cannot get due benefits. Their rights and interests are harmed. On the other hand, it can damage the company's image. For example, if job seekers find that the company does not set legal benefits for employees, they will doubt on the company. It is harmful for enterprise to attract talents.

\subsection{The Problems Existed in the Labor Relationship Management}

\subsubsection{Employees Don't Have the Opportunity to Participate in Management}

Employees participated in the management can enhance their sense of pride and reduce friction between enterprise and employees. It can also increase their loyalty and improve enthusiasm, which are benefit to stable development of the company. But in X Company, employees seldom participate in the management of the enterprise. On the one hand, because of the cultural quality of the employees at junior level is not high, managers think that it is not necessary. On the other hand, the management of the family-owned enterprise forms the culture where senior managers are in charge of the enterprise and make decisions on everything.

\subsubsection{Non-Family Members Is at a Disadvantage}

Family member whose personal accomplishment is not high forms an idea: they have a shelter of senior managers. Even if they make mistakes, it is less possible for them to be investigated. Therefore, unhealthy phenomenon is formed. Once non-family members do not get along well with family members, non-family members will be at a disadvantage. With personal rights unprotected, it will result in the loss of talents and harm company's reputation.

\subsection{Cause Analysis}

\subsubsection{The Disadvantages of Family-Owned Companies}

Family-owned management style has its inherent advantages. Family members have confidence in making the company bigger. It is more cooperative between members. But as the company passes initial stage and goes into its developing stage, the disadvantages of family-owned company will get in the way of its development. From 
practice, firstly, family members' culture quality is not high. Their professional knowledge and skills cannot meet the needs of the enterprise's development. Secondly, the power is concentrated in family members. The decision is made according to member's personal experience. Problems are existed as a result of their narrow vision and lack of supervision and control in making decisions. Thirdly, family members hold more resources. Once non-family members do not get along well with family members, family members may push them out, which is not benefit for attracting talents.

\subsubsection{A Lack of Communication between Managers}

The manager at present was transferred from Shanghai to Tai'an. He doesn't have comprehensive understanding about the present situation of Taishan district. All work goes difficult whether carrying out business activities, or managing internal affairs. It has a certain relationship with less communication with former manager. On the other hand, it takes much time for the boss to have intercourse. Therefore, time to communicate and coordinate is very limited. In addition, communication between foreman and directors is quite less, which is unfavorable for all aspects of human resource work.

\subsubsection{Lack of Professionals and Immature}

X Company's HR department, purchasing department and warehouse department are unified in one office. All stores' assistant does not have real power of HRM. Most of the decisions are made by manager or superior personnel. It is related not only with assistants' poor professional skills, but also with their culture. In the view of six modules of HRM, X Company is short of talents with rich experience and professional skills in HRM.

\subsubsection{Lack of Data Analysis}

For HR department, accurate date like employee turnover, average incumbency time and data producing in the process of recruitment and training can help enterprise to carry out HRM more smoothly. Timely adjustments are helpful for company's development.

\section{Measures to Improve HRM}

\subsection{Scientific Measures for HR Planning}

Combined with developing strategy, it is important for X Company to find the focus and direction of HRM work. Then, concrete schemes and plans are necessary. For X Company, besides the business plans, overall plans should be set up. On the premise of HRM work finished in headquarter; it is proper to guide each store to make human resource plans. In addition, the enterprise should do a good job in the budget for each HRM work, which can avoid waste.

\subsection{Improve the Work of Recruiting and Configuration}

Head of the HR department should choose proper recruitment channels to meet the needs of the enterprise's development. Services are more developing in South district of Tai'an. It is wise to choose employment market where service companies are concentrated. There, attracting talents who are willing to work in the service company is easier. The structure of modern organization tends to be flat. For X Company, it is acceptable to cancel the positions which are foremen and general managers. General Managers can be a member of the board. Cancelling the position of foremen can save human capital. In addition, higher employee turnover is common fault of the family-owned enterprise. Based on reasonable analysis of employee turnover, we should take measures to reduce employee turnover, which is helpful to the stable development of the enterprise.

\subsection{Establishment of a Comprehensive Training System}

Employees' training should be comprehensive. Not only skills training and attitude training, but also knowledge training. Not only training for business department's staff, but also for other departments' staff. Not only conducting regular training, but also carrying on the long-term training. Attention, perfect training system should be included: training service system, the system of pre-job training and job training, evaluation system, rewards and punishment system. In addition, in order to meet the needs of the development, recruiting professional talents, scientific and systematic training for employees are favorable. 


\subsection{Conducting Comprehensive Performance Management}

For X Company, employees of operation department are close to customers. But, the work of other departments can indirectly affect the quality of service. Therefore, performance evaluation should not be confined to managers in operation department. Evaluation for junior staff and other department is required. Secondly, X Company can set up performance indicators for senior managers. What is more, accomplishments should be measured. The board should encourage managers to make every effort for the development.

\subsection{Improve C \& B Management}

Wage differential in the operation department, according to the data analysis, is not big. To maintain the incentive effect, it is feasible to reduce the number of the rank. More importantly, X Company should set up national statutory welfare for the employees. In addition, as for the wages of technician department, X Company can consider to set up the basic wage in off-season. Besides, we should improve their professional quality in their training.

\subsection{Improve the Relationships to Achieve Win-Win Situation}

The relationship between the enterprise and employees has both cooperation aspect and conflict situation. X Company should take active measures to coordinate the contradiction with employees. Moreover, in the process of its development, employees should be allowed to take part in the management, which is benefit to build a harmonious relationship. As a result, it would become an influential company in the future.

\section{Acknowledgements}

This paper is supported by Project of Education, Science and Research of Shandong Province (No.15SC105) and Social Science Project of Shandong Agricultural University (No.23899).

\section{References}

[1] Mitchell, B. (2012) The Big Book of HR. Career Press.

[2] Vahdani, B. and Mousavi, S.M. (2014) Soft Computing-Based Preference Selection Index Method for Human Resource Management. Journal of Intelligent \& Fuzzy Systems: Applications in Engineering and Technology, 26, 393403.

[3] Curtis, B. (2011) People CMM. China Machine Press.

[4] Mondy, R.W.D. (2013) Human Resource Management. Prentice Hall, Upper Saddle River.

[5] Noe, R. (2013) Foudamentals of Human Resource Management. McGraw-Hill Education, New York.

[6] Lussier, R.N. (2012) Human Resource Management: Functions, Applications, Skill Development. SAGE Publications, Inc., Thousand Oaks.

[7] Armstrong, S. (2008) The Essential HR Handbook: A Quick and Handy Resource for Any Manager or HR Professional.

[8] Wang, Y.Z. and Li, L.F. (2013) Intelligent Human Resource Planning System in a Large Petrochemical Enterprise. IEEE Intelligent Systems, 28, 102-106. http://dx.doi.org/10.1109/MIS.2013.112 